\title{
Correction to: LC-MS based metabolic fingerprinting of apricot pistils after self-compatible and self-incompatible pollinations
}

\author{
József Lénárt ${ }^{1,2} \cdot$ Attila Gere $^{3} \cdot$ Tim Causon $^{4} \cdot$ Stephan Hann ${ }^{4} \cdot$ Mihály Dernovics $^{5} \cdot$ Olga Németh $^{1} \cdot$ Attila Hegedüs $^{2}$. \\ Júlia Halász ${ }^{2}$ (D)
}

Published online: 12 January 2021

(c) The Author(s) 2021

\section{Correction to: Plant Molecular Biology \\ https://doi.org/10.1007/s11103-020-01098-5}

In the above mentioned publication, Fig. 3 was incorrect as the panels for SC and SI cultivars were transposed. The original article has been corrected and the proper version of Fig. 3 is also published here.

The original article can be found online at https://doi.org/10.1007/ s11103-020-01098-5.

\section{Júlia Halász}

genetics.prunus@gmail.com

1 Department of Applied Chemistry, Faculty of Food Science, Szent István University, Villányi út 29-43, Budapest 1118, Hungary

2 Department of Genetics and Plant Breeding, Faculty of Horticultural Science, Szent István University, Ménesi út 44, Budapest 1118, Hungary

3 Department of Postharvest Sciences and Sensory Evaluation, Faculty of Food Science, Szent István University, Villányi út 29-43, 1118 Budapest, Hungary

4 Institute of Analytical Chemistry, University of Natural Resources and Life Sciences, Muthgasse 18, 1190 Vienna, Austria

5 Department of Plant Physiology, Agricultural Institute, Centre for Agricultural Research, Brunszvik u. 2, Martonvásár 2462, Hungary 


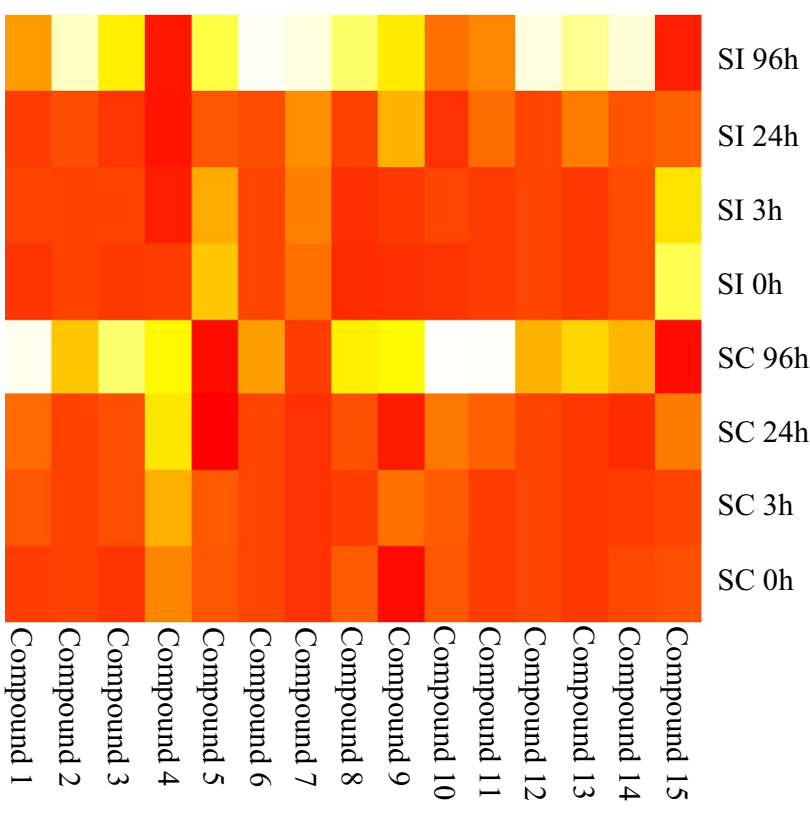

Fig. 3 Heatmap illustration of components differing between incompatible and compatible pollinations and among time intervals $(0,3$, 24 and $96 \mathrm{~h}$ ) after self-pollination. The higher is the intensity of the compound, the darker is its colour

Publisher's Note Springer Nature remains neutral with regard to jurisdictional claims in published maps and institutional affiliations. 